\title{
SIMMEL E GOFFMAN: CONTRIBUIÇÕES PARA O ESTUDO DAS RELAÇÕES SOCIAIS NO AMBIENTE ESCOLAR
}

Maíra Mascarenhas

\section{RESUMO}

O objetivo do trabalho é apresentar as perspectivas e os conceitos elaborados por Georg Simmel e Erving Goffman e pensar de que maneira esses podem contribuir para a compreensão e o estudo das relações sociais construídas na escola. Os trabalhos dos dois autores apresentam um nível de concordância e complementariedade extremamente profícuo para a compreensão das relações sociais construídas pelos sujeitos em contextos de interação, como é o caso da escola. Analisa-se também a acusação como uma forma de sociação que revela valores e categorias que orientam a ação dos atores.

Palavras-chave: Simmel; Goffman; Escola; Acusação; Sociologia.

\section{SIMMEL AND GOFFMAN: CONTRIBUTIONS TO THE STUDY OF SOCIAL RELATIONS IN SCHOOL ENVIRONMENT}

\begin{abstract}
The objective of this paper is to present the perspectives and concepts developed by Georg Simmel and Erving Goffman as well as to explore how these can contribute to the study of social relations established in the school environment. The works of both authors present a level of agreement and complement each other in useful and productive ways for understanding the social relations between subjects in a interactive contexts, such as in a school. Also, the article analyses accusation as a form of sociation that revels values and categories which organize and guide the action of actors.
\end{abstract}

Keywords: Simmel; Goffman; School; Accusation; Sociology 


\section{Introdução}

A proposta do trabalho é pensar as relações sociais construídas na escola a partir da perspectiva e dos conceitos de dois sociólogos: Simmel e Goffman. Os trabalhos dos dois autores apresentam um nível de concordância e complementariedade extremamente profícuo para a compreensão das relações sociais construídas pelos atores em contextos de interação, como é o caso da escola. Esta importância se dá, em especial, por serem autores que analisam a sociedade a partir das microrelações estabelecidas pelos indivíduos nos diferentes contextos e mundos sociais pelos quais transitam.

Georg Simmel (1858-1918) é um pensador interdisciplinar, seus escritos abrangem uma quantidade muito grande de temas e transitam pela sociologia, psicologia, filosofia. Sua contribuição para o pensamento moderno é de suma importância por seu caráter inovador, ainda que isto tenha lhe rendido uma posição marginal no campo da sociologia. Entretanto, seu legado alcançou dimensões importantes nos estudos de microssociologia, em especial, na Escola de Chicago (VELHO, 2008). Sua concepção de sociedade e sua abordagem sociológica exerceram grande influência, entre outros, no pensamento do sociólogo canadense Erving Goffman.

Seguindo a unidade de análise estabelecida por Simmel, os trabalhos de Goffman abordam a sociedade a partir das relações de interação constituídas pelos indivíduos. Goffman parte deste pressuposto metodológico para investigar a subjetividade dos atores e suas estratégias de ação nas relações face a face.

O pensamento de Simmel sobre a incompletude da individualidade na interação e a ideia do autor de diferenciação como um motor para a ação do homem, são de grande importância para entender o processo de construção de identidade dos atores na escola. Somase a eles, o conceito de papel social e a perspectiva de Goffman sobre a representação dos atores perante uma 'plateia'. A noção de estigma como produto de uma perspectiva contextual é também fundamental para a compreensão dos valores e representações que orientam as relações sociais construídas no espaço escolar.

Portanto, parte-se da ideia de que a escola é um espaço de interação entre atores heterogêneos que desempenham papéis sociais pré-determinados macrosocialmente. Desta forma, acredita-se que o repertório teórico de Simmel e Goffman é fundamental para 
compreender quais as formas de interação produzidas no ambiente escolar e também quais as representações e conteúdos que orientam as relações sociais ali construídas.

\section{Simmel: formas, conteúdos e diferenciação}

A sociologia de Simmel pode ser chamada de microssociologia, pois é uma abordagem das interações, que olha para a intersubjetividade dos atores.

A concepção do autor de sociedade é fundada na ideia de interação. Esta constitui a base das relações sociais e dos sistemas de relação. Só existe sociedade onde um número de indivíduos está em interação (1908b). É a consciência desta interação que garante a existência da sociedade, pois é a ciência dos sujeitos de suas relações e ligações com os outros que lhes dão condições de entrar em interação e, assim, constituir a própria sociedade.

Numa interação, um indivíduo influencia e é influenciado por outro, de modo que há uma relação de troca. O que caracteriza a unidade que se forma desta relação - a sociedade - e a distingue de um mero agregado de indivíduos, é o princípio da reciprocidade de efeitos entre as ações individuais. A reciprocidade é um elemento fundamental na teoria simmeliana, pois ela é o que mantém as interações e, consequentemente, a existência da própria sociedade. A reciprocidade é anterior à interação para o indivíduo, uma vez que ela é constitutiva da ordem social. Portanto, para Simmel, a unidade básica de relação social é a interação, sempre orientada e sustentada pela reciprocidade.

Os processos sociais têm como base material a interação, e são eles que a transformam e estruturam através da sociação. As formas de interação, juntamente com os conteúdos, são elementos inseparáveis que compõem os fenômenos sociais. Os conteúdos são os interesses, os fins, as motivações individuais. Eles dizem respeito a tudo que é próprio do indivíduo e que lhe permite engendrar efeitos sobre os outros e receber efeito dos outros. Essas motivações que impulsionam a ação individual não possuem uma natureza social, elas se tornam sociais apenas quando passam a operar na interação.

Já as formas, ou modos de interação entre os indivíduos, são o meio pelo qual os conteúdos se concretizam como realidade social. Surge entre as formas e os conteúdos uma relação de autonomia na qual as formas passam a ter vida própria. Ao invés de estarem atreladas a um determinado conteúdo, passam a exercitar todos os conteúdos. Este processo gera, por consequência, o fenômeno da sociabilidade (SIMMEL, 2006). Isto é, a unidade 
formada pela interação, a sociedade, pressupõe a união entre forma e conteúdo. Os indivíduos entram em interação a fim de satisfazerem seus interesses e esta interação se dá por meio das diferentes formas de sociabilidade, ou seja, formas que são independentes de conteúdos específicos.

Portanto, a interação, sendo regida pelos conteúdos individuais, é uma relação entre individualidades na troca. Entretanto, na interação, não é possível conhecer completamente a individualidade do outro, decorrendo disto que todas as relações entre os homens são pautadas por certo grau de incompletude (Idem, 1908a). Essa incompletude resulta em uma generalização do outro, que implica em pensá-lo não só em termos de sua singularidade, mas também por meio de categorias gerais que não correspondem à realidade. Os indivíduos são percebidos uns pelos outros, por meio de estereótipos ou tomados pelos grupos sociais aos quais pertencem. De um modo ou de outro, a generalização da individualidade alheia nunca dá conta de sua totalidade:

Todas as relações entre os homens são determinadas por certo grau de incompletude. (...) A consequência [desta incompletude] é a generalização da imagem psicológica que nós fazemos do outro (...) Generalização que resulta em pensá-lo não só em termos de sua pura individualidade, mas também em termos de uma categoria geral (...) É precisamente por causa da singularidade de uma dada personalidade que nós construímos uma imagem dela que não é idêntica à realidade da mesma e que, ao mesmo tempo, não coincide com um tipo geral. (Ibidem: 10 , tradução minha)

Por mais que se classifique um indivíduo com base em sua categoria social mais relevante ou seu papel social desempenhado no momento, ele é sempre alguma coisa a mais. O indivíduo tem sempre uma parte social, um conteúdo que é socialmente relevante na interação, e também uma parte não social, que não é acionada na interação, mas que compõe a sua individualidade. Estar, ao mesmo tempo, dentro e fora da sociedade é uma prerrogativa do indivíduo que garante o funcionamento e a existência da vida social.

Um aspecto importante para a formação da subjetividade e da individualidade do homem é a formação de significado prático por meio da semelhança e da diferença (Idem, 2006) O impulso pela diferenciação é, segundo o autor, o que determina a atividade dos indivíduos:

INTRATEXTOS, Rio de Janeiro, 4(1): 240-257, 2012 
É como se cada individualidade sentisse seu significado tão somente em contraposição com os outros, a ponto de essa contraposição ser criada artificialmente onde antes não existia. Pode ocorrer mesmo quando a solidariedade e a unidade que almeja em sua busca de contraste derivam da existência de uma frente unida que se formou com contraposição a outra frente similar. (Ibidem: 46,47)

A diferenciação, portanto, é um impulso, um anseio dos indivíduos. É também uma característica que se liga à estrutura dos grupos. O autor observa uma ligação direta entre a expansão dos grupos sociais e o desenvolvimento da individualidade (Idem, 1908c).

A individualidade de ser e agir geralmente aumenta na medida em que o circulo social que encompassa o indivíduo se expande. Neste sentido, quanto menor for o círculo social no qual o individuo se encontra menor o espaço para sua individualidade. Entretanto, o grupo opera, ele mesmo, como um sujeito: quanto menor, mais singular e distinto em relação ao resto do mundo.

Da mesma forma, o indivíduo que se encontra inserido em um círculo maior, terá mais espaço para desenvolver sua individualidade, ao passo que o grupo tende a ser menos singular. Ou seja, os sujeitos encompassados por grupos maiores são mais diferenciados do que aqueles que se encontram como membros de grupos pequenos. Cabe destacar, que Simmel enfatiza o multipertenciamento dos agentes a diversos círculos sociais de diferentes tamanhos e extensões, o que resulta na impossibilidade de fixar os indivíduos apenas a um grupo de uma determinada configuração.

\section{Goffman: papéis sociais}

A obra de Goffman possui grande influência de Simmel (GERHARDT, 2003). Assim como para o pensador alemão, a interação e a reciprocidade ocupam um papel fundamental na concepção do autor de sociedade. A reciprocidade é o princípio que orienta as interações, pois a expectativa sobre "o outro" e a influência dos atores sobre o comportamento uns dos outros são fatores essenciais para as estratégias e as ações individuais.

Os rituais de interação - assim como as sociações de Simmel - possibilitam a vida social (GOFFMAN, 2011). Eles se caracterizam por serem relações estruturadas que se constroem entre os atores em configurações situacionais e contextuais. Na perspectiva de Goffman, as interações assumem diferentes formas nos diversos contextos. São preenchidas 
com as intenções e motivações dos atores sempre de acordo com a interpretação e o sentido atribuído pelo sujeito a um determinado contexto.

Entretanto, diferentemente de Simmel, que estabeleceu seu foco nas formas, Goffman se preocupou com os conteúdos, com a subjetividade dos atores. Em trabalhos como Estigma: notas sobre a manipulação da identidade deteriorada (2008), A representação do eu na vida cotidiana (2009) e Ritual de interação: ensaios sobre o comportamento face a face (2011), fica explícita a busca do autor por compreender o efeito das emoções e das intenções nas interações face a face.

A discussão sobre a representação do eu (GOFFMAN, 2009) é muito produtiva para a o estudo das relações sociais em um universo micro, como é uma escola. Partindo da perspectiva dramatúrgica, Goffman investiga a maneira pela qual as pessoas se representam na vida cotidiana e como a identidade social é compreendida. Ele parte da ideia de que os indivíduos possuem um conhecimento anterior à interação que lhes permite conhecer ou ter uma impressão inicial do outro. Esse conhecimento pré-adquirido possibilita também desenvolver estatégias de apresentação visando à percepção produzida neste outro. Desta forma, indivíduos conscientes de sua capacidade de projetar uma determinada imagem desejada durante a interação manipulam suas ações a fim de expressar uma ideia de si mesmos e impressionar os outros.

Esta manipulação pode se dar por meio de dois elementos: aqueles que são possíveis de controlar e aqueles que são considerados incontroláveis. Desta forma, a interação é um processo em que os atores estão constantemente se pautando na expectativa do outro e é marcada por um modus vivendi característico:

Os participantes, em conjunto, contribuem para uma única definição geral da situação, que implica não tanto um acordo real sobre o que existe, mas, antes, num acordo real quanto às pretensões de qual pessoa, referentes às quais questões, serão temporariamente acatadas. (Goffman, 2009: 19)

A noção de "definição de situação" é fundamental para compreender a concepção do autor sobre a dinâmica da vida social. O conceito foi usado originalmente em uma obra de William Thomas (1966) e se refere ao processo pelo qual os indivíduos atribuem sentido a um determinado contexto. A “definição de situação" está ligada à construção social da realidade e, por conseguinte, é um conceito indispensável para entender de que maneira as pessoas se 
orientam no mundo. Definir a situação é um mecanismo que permite aos atores entender o que está acontecendo em uma determinada conjuntura e se alinhar adequadamente às diferentes situações.

Portanto, na interação, a definição de situação que os indivíduos formulam é o que lhes permite elaborar estratégias de ação tendo em vista a definição de situação formulada pelo outro. Uma definição de situação errônea pode causar constrangimento (Goffman, 2011) e conflitos levando ao rompimento da expectativa inerente à reciprocidade e, logo, à interação.

A definição de situação é, portanto, gerada a partir da expectativa do comportamento do outro, na medida em que os indivíduos, em um determinado grau, sabem o que esperar uns dos outros. Chega-se aqui a um ponto essencial. Na representação, os indivíduos desempenham papéis sociais que são predefinidos. Goffman define papel social como

a promulgação de direitos e deveres ligados a uma determinada situação
social, podemos dizer que um papel social envolverá um ou mais
movimentos, e que cada um destes pode ser representado pelo ator numa
série de oportunidades para o mesmo tipo de público ou para um público
formado pelas mesmas pessoas. (Goffman, 2009:24)

A representação de um determinado papel na interação pressupõe em certa maneira de agir que expresse as informações sobre o indivíduo que ele deseja transmitir. Estas serão determinantes para que os que se encontram em sua presença possam se localizar e antecipar suas expectativas em relação àquele indivíduo, bem como antever as expectativas do indivíduo em relação a eles. Logo, cabe ao ator manipular sua identidade na representação de forma a projetar uma determinada definição de situação.

A manipulação da identidade é um aspecto importante também em outra obra do autor: Estigma - Notas sobre a manipulação da identidade deteriorada (2008). Novamente, a preocupação de Goffman é com as informações que os indivíduos transmitem sobre si mesmos. O ponto central do livro é a análise dos mecanismos de manipulação da identidade deteriorada, do aspecto da identidade do indivíduo que não condiz com a expectativa e o padrão de normalidade ${ }^{1}$ de uma sociedade.

\footnotetext{
${ }^{1}$ A ideia de normalidade, ainda que controversa, é usada pelo autor. Os termos "estigmatizados" e "normais" fazem parte do vocabulário de Goffman nesta obra.
}

INTRATEXTOS, Rio de Janeiro, 4(1): 240-257, 2012

Página 246 
Goffman inicia o texto apresentando a origem do termo estigma. Em seguida, em consonância com a proposta de Durkheim sobre a origem social dos sistemas de classificação (DURKHEIM, 2000), o autor escreve sobre o caráter coletivo e social das formas de classificação presentes na sociedade e que operam na interação face a face:

A sociedade estabelece os meios de categorizar as pessoas e o total de atributos considerados como comuns e naturais para os membros de cada uma dessas categorias. (Goffman, 2008: 11)

Isto quer dizer que quando um indivíduo se depara com outro em uma situação de interação, ele é levado a categorizá-lo de acordo com as categorias e variáveis existentes no sistema de classificação de sua sociedade. Esta classificação, portanto, depende de elementos “estruturais", anteriores à interação, assim como de representações que adquirem sentido na contingência, no momento do encontro e no contexto específico daquela situação.

Desta forma, a sociedade cria e opera com estereótipos de tipos sociais de indivíduos que devem agir de acordo com as expectativas que correspondem e recaem sobre cada um deles. Na interação face a face, por exemplo, tende-se a acreditar que a performance do outro deve estar de acordo com o que é esperado de seu tipo social.

Esta expectativa implica em uma constante aferição do comportamento alheio. A coletividade cria uma identidade social virtual que expressa os atributos esperados de um indivíduo em contraposição à identidade social real que corresponde aos verdadeiros atributos contidos no indivíduo. O cerne do trabalho de Goffman é investigar dos mecanismos de controle e manipulação da identidade e as consequências da relação discrepante entre o tipo de identidade social virtual e a identidade social real.

Cumpre ressaltar que o estigma na perspectiva do autor é relacional, não é um atributo do indivíduo, mas sim produto de uma relação social, da interação entre indivíduos. Ou seja, o estigma não é referente a uma determinada característica ou a uma pessoa, mas é uma linguagem de relações, de perspectivas que são geradas nas contingências da vida social (GOFFMAN, 2008).

Logo, um indivíduo que é considerado normal em uma dada circunstância pode, de fato, ocultar algum marcador que lhe remeteria à condição de estigmatizado. Sendo assim, os papéis de normal e estigmatizado são intercambiantes dependendo do contexto, pois ao longo da vida os indivíduos acabam desempenhando ambos. 
Esta possibilidade se dá também porque o estigma não constitui a totalidade da identidade dos indivíduos, eles também possuem outras identidades que não são percebidas ou reveladas nos encontros mistos. Esta perspectiva se aproxima da ideia de Simmel de generalização e de incompletude da apreensão da individualidade na interação (SIMMEL, 1908), uma vez que a transitoriedade e o pertencimento a diferentes mundos sociais possibilitam o jogo de múltiplas identidades.

\section{Interação e papéis sociais na escola: trabalho de campo}

Como coloca Malinowski, o objetivo da pesquisa antropológica é "apreender o ponto de vista do nativo, seu relacionamento com a vida, sua visão de seu mundo" (1976:37). Cabe ao etnógrafo buscar os “imponderáveis da vida social", desvelando não só o "esqueleto", mas também a "carne e o sangue" e o "espírito" da cultura nativa. Para tanto, o autor recomenda uma verdadeira imersão do antropólogo no campo.

Inserida nesta perspectiva, iniciei minha pesquisa em um colégio federal do Rio de Janeiro buscando descrever e compreender quais sãos os valores e as categorias que organizam as interações entre alunos e entre alunos e professores. Desde então, acompanho o cotidiano escolar dos atores deste universo: estudantes, professores, diretores, funcionários, estagiários. Frequento duas vezes por semana a escola e transito por seus diversos espaços, tais como: salas de aula, recreio, conselhos de classe, sala da direção, sala dos professores, cantina, reunião de pais, reunião de professores e funcionários, festas e excursões.

Esta escola foi escolhida por já haver uma inserção no campo anterior ao início da pesquisa, pois em 2010 fui estagiária de prática de ensino na instituição e em 2011 me tornei professora de sociologia. A mudança de posição no campo implicou em um deslocamento do olhar. Sendo estagiária, as salas de aula de turmas de $9^{\circ}$ ano do ensino fundamental e de $1^{\circ}$ ano do ensino médio, bem como o recreio, eram meus espaços privilegiados de observação. $\mathrm{Na}$ posição de professora, outros espaços ganharam relevância, tais como a sala dos professores, os conselhos de classe e as reuniões de turma.

Este colégio, que chamarei de $\mathrm{COF}^{2}$, se caracteriza por ser parte da rede federal de ensino. Atende a todo o ensino básico, da alfabetização ao $3^{\circ}$ ano do Ensino Médio, e possui cerca de 800 alunos matriculados distribuídos pelos turnos da manhã e da tarde.

\footnotetext{
${ }^{2}$ Como de praxe nos trabalhos antropológicos, os nomes da instituição e dos atores citados são fictícios.
} 
Conforme os dados me passados pelo próprio colégio, a zona sul do Rio de Janeiro é a região onde se concentra a maior parte das residências dos professores, seguida pela zona norte e a zona oeste, onde moram poucos professores. Entre os alunos, a grande maioria também é composta por moradores da zona sul, mas há também um grande número de moradores da zona norte e alguns do centro e zona oeste.

No espaço escolar os indivíduos estão, a todo o momento, interagindo dentro de determinadas formas, com determinados conteúdos. O ambiente escolar produz diferentes sociabilidades. Ao mesmo tempo, estes indivíduos estão dentro da lógica da diferenciação, eles operam a partir das semelhanças e das diferenças para orientarem suas ações.

A semelhança e a diferença são elementos que produzem identidades. As identidades não são fixas, elas são construídas e negociadas. As pessoas que convivem na escola possuem posições diferentes na sociedade, pois são indivíduos modernos, complexos, com participação em mundos sociais diferentes (SIMEMEL, 1908b; VELHO, 1994). Concomitantemente, cabe a eles interagir representando papéis sociais específicos: o de professor e o de aluno.

Ao desempenharem seus papéis, alunos e professores "jogam” com as definições de situação. Aos alunos, cabe perceber quando é possível se comportar de cada maneira, como por exemplo, quando não conversar enquanto a professora fala a fim de evitar uma sanção. Os professores, por sua vez, escolhem o momento em que irão "chamar a atenção" ou punir seus alunos, com base em expectativas, deles próprios e dos alunos, sobre seu papel social.

Ao representarem seus papéis de aluno e professor, os indivíduos estão submetidos a representar a partir de uma expectativa específica de agir, de falar, de se comportar e de pensar. Desta forma, as singularidades individuais devem se submeter às exigências do papel de maneira que os atores adaptem sua individualidade ao protocolo da representação e não rompam a expectativa de reciprocidade da interação. Ou seja, é preciso manipular as identidades em um jogo de representação/apresentação em que cada um consiga incorporar a identidade de professor e de aluno às identidades que antecedem e extrapolam a vida escolar. A representação de um papel específico parte da matéria prima do que é cada um dos indivíduos, acionando símbolos de status, conteúdos e experiências.

Parte-se do pressuposto de que não é possível congelar as identidades dos indivíduos, pois a interação é determinante para a maneira que o indivíduo se apresenta e se situa em cada contexto. É preciso considerar relações destes indivíduos com a sociedade complexa, suas participações em diversas esferas sociais, a transitoriedade pelos diferentes mundos sociais. 
Todos os agentes que interagem na escola são pessoas que estabelecem relações fora dela e essas relações são parte essencial da individualidade, ainda que possam ser, em um dado momento de interação, componentes da parte não social do indivíduo.

Olhando para dentro da escola, percebe-se que ela é um espaço fundamental de construção de identidade, pois, ao mesmo tempo em que desempenham seus papéis, alunos e professores estão estabelecendo fronteiras e limites na interação. A sala de aula, bem como o recreio, reuniões, e outros espaços da escola, são cenários para os conflitos, afinidades e antipatias resultantes dessa formatação dos atores a seus papéis.

As situações que ocorrem no contexto escolar envolvem sempre negociações de valores e pontos de vista que formam continuidades e descontinuidades entre os indivíduos. Há um jogo entre semelhanças e diferenças que determina a formações de grupos, as diferenciações e também as formas de interação entre os atores. Mas como se dá este jogo? Em que medida determinados grupos se formam e encompassam estes indivíduos? Como então se combinam a representação de um papel social e o impulso de diferenciação dos indivíduos? Quais são as formas de sociabilidade resultantes deste processo?

Um caminho para tentar responder estas perguntas é pensar como estes atores formulam impressões e, consequentemente, classificam uns aos outros. As classificações são produto do pensamento coletivo, pois os sistemas de classificação expressam as representações coletivas de uma sociedade, porquanto guardam uma origem social, são frutos da consciência coletiva (DURKHEIM, 2000). Estes sistemas classificatórios podem ser percebidos na vida social por meio dos processos de acusação - que podem revelar estigmas.

A acusação é um mecanismo de estabelecimento de fronteiras e identidades entre os indivíduos. Ela revela um mapa das relações sociais, indica o espaço que cada um ocupa em uma configuração social, além de expor códigos e concepções morais dos atores (VELHO, 1974). Portanto, as acusações revelam os estigmas e, consequentemente, todo o repertório de categorias disponíveis na sociedade - neste caso, na escola. As acusações expõem não só relações de poder, mas também hierarquias.

Pensando a acusação como uma forma de sociação, a escola propicia a observação deste fenômeno em dois níveis: entre alunos, por meio de brincadeiras e "zoações" feitas ente eles; e entre alunos e professores, por meio da acusação e aplicação de sanções por 
professores a alunos que apresentem comportamentos desviantes ${ }^{3}$, ou seja, alunos que quebram as regras de convivência e de disciplina da escola. Estas acusações se dão, principalmente, na sala de aula e no conselho de classe.

Para pensar a acusação ente os alunos, a zoação praticada entre eles é um excelente recorte na medida em que, feita principalmente por meio de acusações verbais e insinuações, ela revelava quais marcadores e atributos são significativos para os alunos. Isto é, quais características ganham significado no fluxo das interações e são valoradas de forma positiva ou negativa. Esta prática explicita a relação estigmatizante construída entre os alunos e está relacionada ao impulso de diferenciação (SIMMEL, 2006) destes, uma vez que revela a hierarquia que garante a posição de cada estudante em uma turma.

\section{Análise de uma situação social na escola}

Ao longo do trabalho de campo, a zoação apareceu como uma forma de sociabilidade muito recorrente entre os alunos. Pode-se perceber a importância de considerar a zoação como uma forma de interação presente na escola a partir da descrição de duas situações sociais (GLUCKMAN, 2010), presenciadas durante duas aulas de sociologia em uma turma de $9^{\circ}$ ano em $2010^{4}$.

Esta turma é composta por 31 alunos, sendo 17 meninas e 14 meninos com idades entre 13 e 15 anos. Acompanhei durante todo o ano de 2010 as aulas de sociologia ministradas na turma e os conselhos de classe realizados neste período. Além disto, vivenciei o cotidiano dos alunos fora da sala de aula como, por exemplo, durante os recreios.

Em uma das aulas de sociologia que acompanhei, o professor passou um filme sobre travestis para discutir questões sobre gênero. Enquanto ele comentava sobre o filme, um aluno, João, perguntou em tom de deboche para seu colega, Lucas, se ele havia ido à Parada Gay de São Paulo, que ocorrera no fim de semana anterior àquela aula. Lucas riu e disse que esteve lá e encontrou o pai de João. Um terceiro aluno riu e chamou Lucas de "veadinho". A

\footnotetext{
${ }^{3}$ A ideia de comportamentos desviantes está em consonância com a perspectiva de Becker (2008) que considera o desvio como uma manifestação da vida social que envolve uma série de situações e atores. O desvio não é uma qualidade do ato do desviante, e nem tão pouco é uma qualidade da pessoa ou da personalidade do desviante. Ele depende não só da quebra da regra, mas também da resposta que os outros dão a esse ato. O desvio é, por conseguinte, um rótulo aplicado com sucesso.

${ }^{4}$ Ver Mascarenhas e Rangel (no prelo).
}

INTRATEXTOS, Rio de Janeiro, 4(1): 240-257, 2012

Página 251 
turma ouviu a conversa entre os três e também riu da situação. Lucas então fez trejeitos com a mão imitando caricaturalmente um gay e riu da brincadeira do colega. O professor reagiu pedindo silêncio e pedindo respeito à Parada Gay, pois é um evento importante que merece respeito.

Em outro momento, em um debate com esta mesma turma sobre gênero e homossexualidade realizado por mim e por estagiários de prática de ensino ${ }^{5}$, os alunos se dividiram com relação às posições sobre as diversas questões levantadas: se os gays já nascem gays, se todo gay é igual, sobre adoção de crianças por casais gays, entre outras. Os meninos, em sua maioria, defenderam posições negativas sobre os homossexuais, muitos admitindo que não manteriam amizade com um, enquanto as meninas foram mais positivas e menos restritivas em relação aos gays.

Em um determinado momento, um aluno, Gabriel, defendeu que as pessoas deveriam experimentar "ficar" com outras do mesmo sexo para saberem se gostam ou não. Muitas meninas concordaram com ele e Lucas, animado e rindo, falou que elas (meninas) realmente deveriam experimentar. Renato, outro aluno, rapidamente falou para Lucas "Que isso? Você acha que tem que experimentar de tudo?". Lucas respondeu que não, que "não era isso" que ele queria dizer, e Renato imediatamente gritou "veado". Renato e outros meninos riram e começaram a fazer brincadeirinhas com Lucas e a situação sem que isso gerasse qualquer alteração no clima amistoso do debate.

Em seguida, foi perguntado para os alunos se eles se incomodariam se uma menina quisesse ficar com eles e todos responderam que não. Logo depois perguntamos se geraria aborrecimentos caso um menino se insinuasse. Todos se manifestaram contra esta possibilidade e Gabriel disse que seria muito ofensivo se um menino quisesse ficar com ele. Uma aluna então perguntou o porquê e Gabriel respondeu com o tom de voz elevado: "Porque eu gosto de meninas!". Neste momento toda turma começou a cochichar e a rir. Um menino falou "Que isso? Duvido!" para Gabriel, que reagiu indignado fazendo com que fosse necessário intervir no debate para apartar a discussão.

Todos os alunos desta turma com quem conversei insinuaram que Gabriel era gay. Entre as características destacadas estava o fato de que "dá para ver", de ele ser "afetado" e

\footnotetext{
${ }^{5} \mathrm{O}$ debate foi conduzido pelos estagiários.

${ }^{6}$ Ficar: se relacionar com outra pessoa apenas por uma noite ou um curto período.
}

INTRATEXTOS, Rio de Janeiro, 4(1): 240-257, 2012 
só andar com meninas. Durante a observação de outras aulas, em diversos momentos surgiram zoações, piadas e insinuações quase sussurradas de que Gabriel era homossexual.

Entre os professores, também havia esta percepção em relação a Gabriel. Em um conselho de classe, uma professora, ao se referir a ele, disse "ele tem aquele jeitinho [fazendo trejeitos com as mãos e em tom irônico]. O Fernando [aluno da turma] diz aquele gay do Gabriel." Fica claro na fala da professora não só sua representação sobre o aluno, mas também a ciência de que entre os alunos também há este tipo de classificação e acusação. A reação dos outros professores participantes do conselho foi de concordância com a fala desta professora e alguns acrescentaram críticas a Gabriel e "seu jeito de ser".

Nas situações descritas, o que chama a atenção é a diferença de sentido em relação à categoria "gay". No que se refere às brincadeiras entre os meninos, tanto na aula sobre o filme quanto no debate, as palavras "gay" e "veado" foram usadas sem pudor e não causaram animosidade. Ao contrário, na situação envolvendo Gabriel, um aluno já estigmatizado por alunos e professores, apenas a insinuação por meio de uma provocação foi suficiente para que surgisse uma hostilidade entre ele e os colegas. "Gay" e "veado", que ouvis frequentemente em outras situações de brincadeiras observadas entre meninos de outras turmas, foram usados sem hesitação por João e Renato ao se referirem a Lucas, mas não foram usadas em relação a Gabriel. A fluidez do sentido de gay, ou da insinuação de ser gay, indica como a percepção e significação, negativa ou não, de categorias e práticas está ligada a contextos de interação.

Apesar desta situação narrada, que demonstra o estigma de Gabriel entre os colegas, ele é visto pelos professores como o aluno que mobiliza a turma. No conselho de classe, ele foi apontado como o "problema da turma", o aluno que deveria ser "isolado". Segundo uma professora, Gabriel criou uma "persona invasiva", "agressiva e de desrespeito com o outro", "ele faz com que a turma só aceite quem ele aceita". Ele seria o responsável por espalhar o boato de que a professora de Educação Física estava grávida e também o responsável pela briga entre dois alunos da turma, pois debochava da voz de um deles e "incentivou" o outro a implicar com o primeiro - o que desencadeou a briga.

Ao longo do trabalho de campo percebeu-se que Gabriel sempre se sentava no mesmo lugar da sala e estava sempre com as mesmas meninas. Durante as aulas, ele oscilava entre um comportamento disciplinado, fazendo perguntas e respondendo as perguntas feitas pela professora, e um comportamento mais indisciplinado, conversando com os alunos sentados perto dele e fazendo intervenções na aula que não tinham a ver com o assunto que estava 
sendo trabalhado pela professora. Quando seu comportamento era indisciplinado, os alunos a sua volta se envolviam em "conversas paralelas" e, de forma geral, a turma ficava mais agitada. Quando isso acontecia, a professora comentava comigo que a aula não havia sido muito boa, que os alunos estavam inquietos e não prestaram muita atenção.

Dentre os alunos de sua turma, o $9^{\circ} \mathrm{A}$, Gabriel era o que mais fazia piadas e brincadeiras com outros alunos tais como: chamar um aluno mais baixo de baixinho e de bebê; rir do cabelo cacheado de outro colega e chamá-lo de palha de aço; zoar a voz de um aluno que tem câncer e, por isso, a voz fina e rouca; chamar um aluno que dorme durante a aula de soneca.

Como já dito, Gabriel era apontado por seus colegas e por seus professores como gay, além disto, constatou-se também que ele era o aluno mais escuro da turma. Têm-se aí dois marcadores sociais que são associados pelo senso comum a uma posição de inferioridade. No entanto, o que a observação mostrou é que Gabriel ocupava uma posição de poder dentro da turma, pois ele impunha classificações aos colegas e também tinha um papel determinante para o desenvolvimento das aulas. Em algumas situações ocupava o papel de desviante, "o gay da turma", sem que isso lhe impedisse de, em outros momentos, impor classificações e, consequentemente, imputar estigmas.

Apesar de ser estigmatizado por seus colegas e confrontado quanto à sua identidade sexual, Gabriel possuía outras identidades e desempenhava papéis diferentes em outras situações de interação. Pensando a acusação como uma forma que se repete em outros contextos e que realiza conteúdos diferentes, o aluno não era sempre o acusado, em muitos casos, era também o acusador. E, para desempenhar cada papel, interagia a partir de sentimentos e motivações (conteúdos) variados.

Neste sentido, essa interação descrita remete à ressalva feita por Simmel quanto à impossibilidade de apreensão da totalidade da individualidade dos atores. Essa incompletude a que o autor se refere é o que permite que Gabriel manipule sua identidade e exerça os diferentes papéis, sem que se produza, necessariamente, o mesmo padrão de interação.

Esta proposição vai de encontro com a perspectiva de Goffman do estigma como uma linguagem de relações e com a possibilidade ressaltada pelo autor de que os indivíduos podem desempenhar os dois papéis, de estigmatizados e de normais, nas diferentes conexões e fases da vida. 
Sendo o estigma produto de uma relação que é fruto de uma situação de inteiração, é possível compreender porque "gay" não era uma categoria de acusação para Lucas, mas era uma categoria estigmatizante para Gabriel. Nas brincadeiras com Lucas o clima era de descontração enquanto a situação envolvendo Gabriel teve como marco a tensão, como descrita por Goffman, típica da relação entre estigmatizados e normais.

Diferentemente de Lucas, Gabriel tinha símbolos de estigma identificados por pelos colegas, como transparece nas falas dos alunos (“dá para ver"; "é afetado"; "só anda com meninas"). Ainda que houvesse a tentativa por parte de Gabriel em manipular sua identidade controlando informações - alegando que gostava de meninas, por exemplo - seu esforço não se sobrepunha a estes símbolos identificados pelos colegas.

A comparação do efeito que a categoria "gay" produziu nas duas situações descritas remete a um aspecto fundamental da interação decorrente de seu caráter de reciprocidade, como assinalada pelos autores. Na medida em que é produto da troca, a sequência de uma situação de interação depende da definição de situação dos atores envolvidos. Portanto podese pensar que também os processos de acusação - entre eles, a zoação - e seus desdobramentos, são condicionados pelas interpretações e sentidos atribuídos a eles pelos envolvidos.

Desta forma, estes processos são permeados de ambiguidade ${ }^{7}$, podendo se manter como uma expressão de camaradagem e respeito ou, ao contrário, como uma manifestação de hostilidade produzindo constrangimentos e humilhação.

\section{Conclusão}

A escola pode pensada como um microcosmo da sociedade, onde se pode encontrar variados tipos sociais e também valores e representações presentes na sociedade mais ampla. É um espaço que reúne indivíduos que pertencem e circulam por diversos mundos sociais e trazem para a vivência escolar toda a experiência e os conteúdos decorrentes deste multipertencimento.

A escola, em si mesma, se configura como destes mundos sociais. Ela possui uma cultura interna resultante de suas próprias dinâmicas. Neste sentido, ainda que resguarde

\footnotetext{
${ }^{7}$ Essa ambiguidade pode ser relacionada às joking relationships descritas por Radcliffe-Brown (1973) no contexto africano. Sobre isto ver Mascarenhas e Rangel (no prelo).
}

INTRATEXTOS, Rio de Janeiro, 4(1): 240-257, 2012 
relações com a esfera macrossocial, o espaço escolar também é organizado por lógicas e por valores que se constroem no nível micro, próprio da escola e das relações que são estabelecidas neste domínio.

Neste sentido, para uma análise das relações sociais e dos processos classificatórios que operam na escola, em especial os processos de acusação, é imprescindível não perder de vista que sentido das relações e das categorias acionadas pelos indivíduos não podem ser tomados de antemão.

Sendo assim, a perspectiva interacionista de Simmel e Goffman contribui para a compreensão desses fenômenos na medida em que lança luz sobre a importância de uma análise contextual que leve em conta as múltiplas possibilidades que perpassam o espaço de significação e de agência dos atores. Do ponto de vista do interacionismo, qualquer tentativa de universalismo ou de determinismo da ação perde o sentido quando se entende que as interações devem ser analisadas em seu contexto.

\section{Referências Bibliográficas}

DURKHEIM, Émile. As formas elementares da vida religiosa. São Paulo: Martins Fontes. 2000.

GERHARDT, U. "Of kindred spirit: Erving Goffman's oeuvre and its relationship to Georg Simmel”. In: TREVIÑO, A. Javier (org.). Goffman's legacy. Boulder/Nova York/Toronto/Oxford: Rowman \& Littlefield Publishers. 2003.

GLUCKMAN, Max. Análise de uma situação social na Zululândia moderna. In: FELDMANBIANCO, Bela. Antropologia das sociedades contemporâneas: métodos. São Paulo: Ed. UNESP. 2010

GOFFMAN, Erving. Estigma: notas sobre a manipulação da identidade deteriorada. Rio de Janeiro: LTC. 2008.

2009.

A representação do eu na vida cotidiana. Petrópolis: Ed. Vozes.

.. Ritual de interação: ensaios sobre o comportamento face a face.

Petrópolis: Ed. Vozes. 2011

INTRATEXTOS, Rio de Janeiro, 4(1): 240-257, 2012

Página 256 
MALINOWSKI, Bronislaw. Os argonautas do Pacífico Ocidental. São Paulo: Abril Cultural. 1976

MASCARENHAS, Maíra, RANGEL, Everton. “Alhos e bugalhos: notas sobre a produção de estigmas em duas escolas cariocas”. In: MAGGIE, Yvonne, PRADO, Ana Pires (orgs). Queremos ter uma vida melhor que a de nossos pais, (no prelo).

RADCLIFFE-BROWN, Alfred R. Apontamentos sobre a relação de brincadeira. In:__ _ Estrutura e Função nas Sociedades Primitivas. Lisboa: Edições 70. 1973

SIMMEL, Georg. "How is Society Possible?" 1908a. In: DONALD, Levine (org). On individuality and social forms. Chicago: The University of Chicago Press. 1971

"The problem of Sociology". 1908b. In: On individuality and social forms. Chicago: The University of Chicago Press. 1971

"Group expansion and the development of individuality". 1908c. In: Press. 1971. .On individuality and social forms. Chicago: The University of Chicago

"As grandes cidades e a vida do espírito". In Mana: estudos de antropologia social, vol. 11, n. 2, outubro, pp. 577-592. 2005.

Janeiro: Ed. Zahar. 2006.

Questões fundamentais da sociologia: indivíduo e sociedade. Rio de THOMAS, William. On social organization and social personality. Selected papers. Chicago: The University of Chicago Press. 1966

VELHO, Gilberto. Projeto e metamorfose: antropologia das sociedades complexas. Rio de Janeiro: Ed. Zahar. 1994.

"Goffman, mal-entendidos e riscos interacionais". Revista Brasileira de Ciências Sociais, vol. 23, núm. 68, outubro, pp. 145-148. 2008. 